Hideo Hirakata MD, *

Kumi Nakamura $M D, \dagger$

Satoko Sai MD, *

Hiroto Okuda MD, *

Yoshio Hatano MD,

Nobukata Urabe $M D$,

Kenjiro Mori MD FRCA ${ }^{\dagger}$

\section{Platelet aggregation is impaired during anaesthesia with sevoflurane but not with isoflurane}

Purpose: Halothane suppresses platelet aggregation in vitro and ex vivo, and prolongs bleeding time. In a previous in vitro study we demonstrated that sevoflurane had a more suppressive effect on platelet aggregation than did halothane. The present study irvestigated whether the clinical use of sevofurane affected platelet aggregation ex vivo. Methods: Thirty-eight patients undergoing minor elective surgery were divided randomly into sevoflurane and isoflurane groups. Anaesthesia was induced with thiopentone $w$, and was maintained with sevoflurane or isoflurane with nitrous oxide. Blood was collected to measure platelet aggregation induced by adenosine diphosphate (ADP) and epinephrine. The first (control) blood collection was performed in the operating room before induction of anaesthesia, and the second 5-10 min after tracheal intubation but before the start of surgery. when the end-expiratory sevofurane or isoflurane concentrations had stabilised at $1-1.5$ times the minimum alveolar concentration (MAC) and mean arterial pressures were between 80-120\% of preanaesthetic values.

Results: In all samples obtained during sevoflurane anaesthesia $(n=15)$. ADP and epinephrine could not induce secondary aggregation, although they did induce primary aggregation. In contrast, in the isoflurane group, both primary and secondary aggregation were observed in 14 out of 15 patients, and secondary aggregation was abolished in only one of the samples obtained during anaesthesia.

Conclusion: Sevoflurane, but not isoflurane, alters platelet aggregation in the clinical situation, possibly by suppression of thromboxane $A_{2}$ formation.

Objectif : L'halothane inhibe l'agrégation plaquettaire in vitro et in vivo et prolonge le temps de saignement. Nous avons antérieurement démontré que le sévoflurane avait un effet inhibiteur in vitro plus important sur l'agrégation plaquettaire que l'halothane. La présente étude a pour but de vérifier si l'usage clinique du sévoflurane affecte l'agrégation plaquettaire in vivo.

Méthodes : Trente-huit patients soumis à une chirurgie élective mineure répartis au hasard en groupe sévoflurane et groupe isoflurane participaient à l'étude. L'anesthésie était induite au thiopental $\dot{w}$, et entretenue au sévoflurane ou à l'isoflurane avec du protoxyde d'azote. Du sang était recueilli pour la mesure de l'agrégation plaquettaire induite par le diphosphate d'adénosine (ADP) et l'épinéphrine. Le premier échantillon sanguin (contrôle) était recueilli en salle d'opération avant l'induction de l'anesthésie et le second, 5-10 min après l'intubation trachéale et avant le début de l'intervention après stabilisation des concentrations télé-expiratoires de sévoflurane et d'isoflurane à $1-1,5$ fois la concentration alvéolaire minimale (MAC) de même que de la pression artérielle moyenne d $80-120 \%$ des valeurs préanesthésiques.

Récultats : Majgré une agrégation primaire, l'ADP et l'épinéphrine n'ont induit l'agrégation secondaire dans aucun des échantillons recueillis sous anesthésie au sévoflurane $(n=15)$. Par contre, on a observé dans le groupe isoflurane une aggrégation tant primaire que secondaire chez 14 des 15 patients, l'agrégation secondaire n'ayant été abolie que chez un seul des patients.

Conclusion : En clinique, le sévoflurane contrairement à l'isoflurane altère l'agrégation plaquettaire possiblement par suppression de la formation de thromboxane $A_{2}$.

From the Departments of Anesthesia, Kitano Hospital, ${ }^{\star}$ Osaka 530, Kyoto University Hospital, † Kyoto 606-01, and Wakayama Medical Collage, $¥$ Wakayama 640 , Japan.

Address correspondence to: Dr. Hideo Hirakata, Department of Anesthesia, Kyoto University Hospital, 54 Syogoin-kawahara-cho, Sakyo-ku, Kyoto 606-01, Japan; Phone: 81-75-751-3435; Fax: 81-75-752-3259.

This study was presented in part at the annual meeting of the American Society of Aresthesiologists in New Orleans, 1996.

Accepted for publication August 2, 1997. 


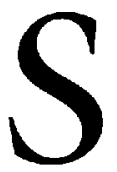

OME anaesthetics possess strong antiaggregatory action and their use may increase surgical bleeding or haemorrhagic complications. However, they may exert a beneficial action by decreasing the risk of thrombogenetic complications during the perioperative period. Previous investigators have demonstrated the anti-aggregatory effects of halothane in vitro ${ }^{1-4}$ and in vivo. ${ }^{5-8}$ Dalsgaard-Nielson et al. ${ }^{6}$ showed that platelet aggregation is affected in blood obtained during halothane anaesthesia, which resulted in prolongation of bleeding time. Gibbs ${ }^{7}$ demonstrated that isoflurane, in contrast to halothane, did not affect platelet function $e x$ vivo. However, information regarding the effect of newer anaesthetics, including sevoflurane, on platelet function is limited.

In previous in vitro studies ${ }^{9,10}$ we found that the anti-aggregatory potencies of volatile anaesthetics were in the order sevoflurane $>$ halothane $>$ isoflurane and enflurane, on a minimum alveolar concentration (MAC) basis. Sevoflurane suppressed ADP- and epinephrine-induced secondary platelet aggregation strongly, possibly by suppression of cyclooxygenase activity. However, no study has evaluated the effect of sevoflurane on platelet aggregation during clinical use. The present study was conducted to investigate the effects of sevoflurane on $e x$ vivo platelet aggregation and its mechanism in the clinical setting. Isoflurane was used in the control group because it is known not to affect platelet function. $7,9,10$

\section{Methods}

After approval of the institutional ethics committee, and obtaining informed consent, 38 patients undergoing minor elective surgery were included in the study. The patients were randomly divided into sevoflurane and isoflurane groups. None of the patients had a history of haematological disorder and none had taken drugs known to affect platelet aggregation for at least two weeks. Preoperative measurements including complete blood count, platelet count, prothrombin time, partial thromboplastin time, electrolyte concentration, and arterial blood gas tensions were within normal limits. The patients were premedicated with $50 \mathrm{mg}$ ranitidine $i m$.

Anaesthesia was induced with $3-5 \mathrm{mg} \cdot \mathrm{kg}^{-1}$ thiopentone and $0.1-0.15 \mathrm{mg} \cdot \mathrm{kg}^{-1}$ vecuronium $i p$, and was maintained with the volatile anaesthetic to be tested with $66 \%$ nitrous oxide in oxygen. After tracheal intubation, inspiratory and end-expiratory vapour gas concentrations were monitored (Datex Capnomac Ultima, DATEX Instrumentarium Corp, Helsinki, Finland). Inspiratory concentrations of the volatile anaesthetics were adjusted to maintain the end-expiratory concentrations at between $\mathrm{l}$ and 1.5 MAC and mean arterial pres- sures between $80-120 \%$ of their preanaesthetic values. Lactated Ringer's solution was infused and no other drug was administered during this period. We used a warmer blanket to prevent hypothermia and body temperature was maintained between 35 and $37^{\circ} \mathrm{C}$ in all cases. Patients in whom preanaesthetic control values indicated impaired platelet aggregation and in those for whom mean arterial pressure could not be maintained within $80-120 \%$ of the preanaesthetic value during the test period were excluded from further studies.

Venous blood was obtained from large veins in the forearm and placed into tubes containing a $10 \%$ volume of trisodium citrate $3.8 \% \mathrm{w} / \mathrm{v}$. The test tubes were sealed tightly with parafilm to minimize evaporation of the anaesthetics. In our previous study ${ }^{10}$ we confirmed by gas chromatography that the concentration of halothane and isoflurane in the sealing tubes were maintained $>90 \%$ for $30 \mathrm{~min}$ at $37^{\circ} \mathrm{C}$. The blood was centrifuged at $160 \mathrm{~g}$ for $10 \mathrm{~min}$ to prepare platelet-rich plasma (PRP), or at $1600 \mathrm{~g}$ for $30 \mathrm{~min}$ to prepare platelet-poor plasma (PPP). Both the PRP and PPP were then stored at room temperature for $30 \mathrm{~min}$. An aliquot $(200 \mu \mathrm{l})$ of PRP was placed into a siliconized glass tube, warmed to $37^{\circ} \mathrm{C}$ for a few minutes before analysis, and stirred continuously both before and during the experiments. Platelet aggregation induced by ADP $(1-10 \mu \mathrm{M})$ and epinephrine $(1-10 \mu \mathrm{M})$ was measured at $37^{\circ} \mathrm{C}$ by recording the increase in light transmission using an 8-channel aggregometer (MCM Hematracer VI MC Medical Inc., Tokyo, Japan). The light transmission of untreated PPP was taken as $100 \%$. The drugs used were sevoflurane (Maruishi Pharmaceutical Co., Ltd., Osaka, Japan), isoflurane (Dainabot, Osaka, Japan), epinephrine hydrochloride (Sigma, St. Louis, MO, USA) and ADP (Sigma). In a preliminary study, the concentrations of volatile anaesthetics in the platelet suspension contained in parafilm-sealed tubes were not significantly altered by the $30 \mathrm{~min}$ incubation at $37^{\circ} \mathrm{C}$.

Data are expressed as means $\pm \mathrm{SD}$ and were analyzed by Student's t test for unpaired data. Male/female and ASA physical status were analyzed by Fisher's exact probability test. Differences at $P<0.05$ were considered to be significant.

\section{Experimental protocol}

Blood collection was carried out in the operating room immediately before induction of anaesthesia (preanaesthetic control, $\mathrm{T} 0$ ) and at 5-10 min after tracheal intubation when the end-expiratory sevoflurane or isoflurane concentration was between 1.0-1.5 MAC (2.1-3.1\% and $1.2-1.8 \%$, respectively) (Tl) ${ }^{11,12}$ The threshold concentrations of ADP and epinephrine used to induce secondary aggregation were determined in the preanaesthetic control PRP, and a PRP obtained during anaesthe- 
sia was exposed to these agonists at concentrations higher than their preoperative thresholds.

\section{Results}

There were no differences between the two groups in age, body weight, sex, American Society of Anesthesiologists (ASA) physical status (Table I), or in blood pressure or heart rate (Table II). In three patients, in the isoflurane group, and one in the sevoflurane group, the mean arterial pressure at $\mathrm{Tl}$ was outside the $80-120 \%$ of preanaesthetic value range. These patients were excluded from further studies. Doses of anaesthetics administered at $\mathrm{Tl}$, and blood pressure and heart rate at $\mathrm{T} 0$ and $\mathrm{Tl}$, are shown in Table II.

Four patients had impaired platelet aggregation at T0, and were excluded from further study. Seven minute measurement of ADP (1-10 $\mu M)$ and epinephrine (1-10 $\mu M)$ induced platelet aggregation, using preanaesthetic control PRP obtained from the remaining 30 patients at T0, showed that primary aggregation was followed by secondary aggregation. The threshold concentrations of $\mathrm{ADP}$ and epinephrine capable of inducing secondary aggregation averaged $3.75 \pm 1.68 \mu \mathrm{M}$ and $3.93 \pm 2.18$ $\mu \mathrm{M}$, respectively, in preanaesthetic control (T0) PRP. Seven minute measurement of platelet aggregation using samples obtained during sevoflurane anaesthesia at $\mathrm{Tl}$, revealed that ADP and epinephrine at 1.2 times the preanaesthetic threshold concentration could not induce secondary aggregation, although they did induce primary aggregation in the all cases ( $n=15$ ) (Figure 1 ). In contrast, in the isoflurane group, both primary and secondary aggregation was observed in 14 out of 15 patients, and secondary aggregation was abolished in only one of the samples obtained during anaesthesia (Figure 2). Volatile anaesthetics inhibited platelet secondary aggregation completely or did not affect it at all at least in our experimental condition.

TABLE I Demographic data of patients studied

\begin{tabular}{llllll}
\hline & Age & $M / F$ & Body weight & ASA I/II & $\begin{array}{l}\text { Platelet count } \\
(\times 10,000)\end{array}$ \\
\hline Sevoflurane & $45.5 \pm 12.6$ & $1 / 14$ & $52.5 \pm 8.3$ & $10 / 5$ & $25.7 \pm 6.4$ \\
Isoflurane & $48.2 \pm 17.4$ & $3 / 12$ & $57.2 \pm 11.5$ & $12 / 3$ & $24.7 \pm 6.0$ \\
\hline
\end{tabular}

$P=$ NS between groups.
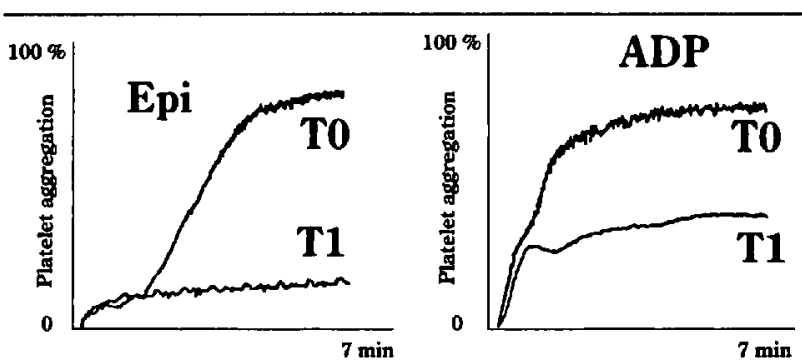

FIGURE 1 Typical recordings of epinephrine $(3 \mu \mathrm{M})$ - and $\mathrm{ADP}(3 \mu \mathrm{M})$-induced platelet aggregation of PRP obtained right before induction of anaesthesia (T0) and during anaesthesia with sevoflurane $(\mathrm{Tl})$.

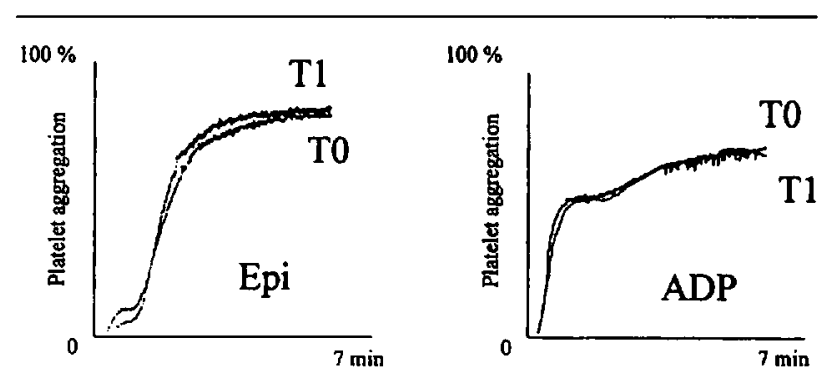

FIGURE 2 Typical recordings of epinephrine $(3 \mu \mathrm{M})$ - and $\operatorname{ADP}(3 \mu \mathrm{M})$-induced platelet aggregation of PRP obtained right before induction of anaesthesia (T0) and during anaesthesia with isoflurane (T1).

TABLE II Doses of anaesthetics administered and cardiovascular variable at test period

\begin{tabular}{|c|c|c|c|c|c|c|c|}
\hline & $\begin{array}{l}\text { Doses adminis } \\
\text { Thiopentone } \\
\left(\mathrm{mg} \cdot \mathrm{kg}^{-1}\right)\end{array}$ & $\begin{array}{l}\text { d between TO and } T 1 \\
\text { Vecronium } \\
\left(\mathrm{mg} \cdot \mathrm{kg}^{-1}\right)\end{array}$ & $\begin{array}{l}\text { Volatile anaesthetics } \\
\text { Concentration } \\
\text { (MAC) }\end{array}$ & $\begin{array}{l}\text { Blood pressure } \\
\text { (mmHg) } \\
\text { T0 }\end{array}$ & $\mathrm{Tl}$ & $\begin{array}{l}\text { Heart rate } \\
\left(1 \cdot \mathrm{min}^{-1}\right) \\
\text { T0 }\end{array}$ & $\mathrm{Tl}$ \\
\hline Sevoflurane & $3.62 \pm 0.69$ & $0.126 \pm 0.024$ & $1.41 \pm 0.185$ & $86.1 \pm 9.2$ & $87.6 \pm 13.3$ & $77.4 \pm 15.0$ & $79.7 \pm 13.4$ \\
\hline Isoflurane & $3.92 \pm 0.67$ & $0.130 \pm 0.027$ & $1.44 \pm 0.146$ & $89.2 \pm 10.8$ & $80.5 \pm 12.3$ & $75.8 \pm 13.1$ & $81.7 \pm 14.1$ \\
\hline
\end{tabular}

$\mathrm{T} 0$ and $\mathrm{T} 1$ represents time when the first (pre-anaesthesia) and second measurements were performed.

Mean \pm SD

There were no difference in doses of anaesthetics or cardiovascular variables between groups. 


\section{Discussion}

In the present study, platelet aggregation was suppressed in all 15 patients after $<20 \mathrm{~min}$ anaesthesia with sevoflurane at 1 to $1.5 \mathrm{MAC}$, but was suppressed in only one out of 15 patients anaesthetized with isoflurane. These results indicate that the effect of sevoflurane on platelet function is greater than that of isoflurane even at clinical anaesthetic concentrations.

In PRP obtained during sevoflurane anaesthesia, ADP- and epinephrine-induced secondary aggregation was selectively affected without altering primary aggregation. The binding of weak agonists, such as ADP and epinephrine, to platelets activates phospholipase $A_{2}$ to release arachidonic acid. Arachidonic acid is then converted to prostaglandin $\mathrm{G}_{2}\left(\mathrm{PGG}_{2}\right)$ and finally to thromboxane $A_{2}$ (TXA $)_{2}{ }^{13}$ which plays a major role in the induction of secondary aggregation. Therefore, inhibition of secondary aggregation without any alteration in primary aggregation is considered to result from suppression of the formation and/or function of TXA $\mathrm{T}_{2}$. The present findings are in agreement with our previous in vitro findings..$^{9,10}$

Previously, we showed that sevoflurane suppressed platelet aggregation by inhibiting TXA formation but

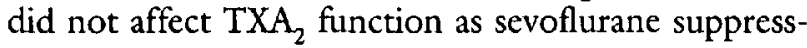
es arachidonic acid-induced platelet aggregation and $\mathrm{TXB}_{2}$ formation but does not affect TXA ${ }_{2}$ analoginduced aggregation. ${ }^{10}$ The present findings that clinical concentrations of sevoflurane suppressed platelet secondary aggregation without affecting primary aggregation are in agreement with the above mechanism, indicating that inhibition of TXA $\mathrm{A}_{2}$ formation occurs during anaesthesia with sevoflurane.

Although aggregation induced by lower concentrations of epinephrine was suppressed by halothane and sevoflurane, the aggregation induced by higher concentrations of epinephrine was reversed. During general anaesthesia, surgical stress induces endocrine responses and sympathetic activation. Therefore, during or after invasive surgical procedures, the antiaggregatory effect of anaesthetics may be overcome by increased catecholamine concentrations. This, in addition to the large variability of individual conditions encountered in clinical situations, may explain why only a few investigators have confirmed the increased blood loss during general anaesthesia when compared with epidural anaesthesia. ${ }^{14-17}$

We speculate that the suppressive effects of anaesthetics on platelet aggregation might be deleterious in certain clinical situations, for example in patients with known platelet disorders or massive haemorrhage requiring massive transfusion. Conversely, these suppressive effects on platelets could be beneficial in patients with complications such as ischaemic heart disease, as $\mathrm{TXA}_{2}$ released from platelets would be expected to increase myocardial damage in patients with acute myocardial ischaemia. ${ }^{18-22}$

We conclude that sevoflurane but not isoflurane can suppress platelet aggregation even in the clinical situation. We should take the present findings into consideration when we choose anaesthetics for patients in certain situations. Further studies under more varied conditions, including invasive surgical interventions may be required to confirm this.

\section{References}

1 Ueda I. The effects of volatile general anesthetics on adenosine diphasphate-induced platelet aggregation. Anesthesiology 1971; 34: 405-8

2 Walter F, Vulliemoz $Y$, Verosky M, Triner L. Effects of halothane on the cyclic $3^{\prime}, 5^{\prime}$-adenosine monophosphate enzyme system in human platelets. Anesth Analg 1980; 59: 856-61.

3 Dalsgaard-Nielsen J, Gormsen J. Effects of halothane on platelet function. Thromb Haemost 1980; 44: 143-5.

4 Kobro S, Yamakage M. Direct inhibitory mechanisms of halothane on human platelet aggregation.

Anesthesiology 1996; 85: 96-106.

5 Fyman PN, Triner L, Schranz H, et al. Effect of volatile anaesthetics and nitrous oxide-fentanyl anaesthesia on bleeding time. Br J Anaesth 1984; 56: 1197-200.

6 Dalsgaard-Nielsen J, Risbo A, Simmelkjaer P, Gormsen J. Impaired platelet aggregation and increased bleeding time during general anaesthesia with halothane. Br J Anaesth 1981; 53: 1039-42.

7 Gibbs NM. The effect of anaesthetics agents on platelet function. Anaesth Intensive Care 1991; 19: 495-520.

8 Sweeney $D$, Williams $V$. The effect of halothane general anaesthesia on platelet function. Anaesth Intensive Care 1987; 15: 278-81.

9 Hirakata $H$, Ushikubi F, Narumiya S, Hatano $Y$, Nakamura K, Mori $K$. The effect of inhaled anesthetics on the platelet aggregation and the ligand-binding affinity of the platelet thromboxane $\mathrm{A}_{2}$ receptor. Anesth Analg 1995; 81: 114-8.

10 Hirakata $H$, Ushikubi $F$, Toda $H$, et al. Sevoflurane inhibits human platelet aggregation and thromboxane $\mathrm{A}_{2}$ formation, possibly by suppression of cyclo-oxygenase activity. Anesthesiology 1996; 85: 1447-53.

11 Quasha AL, Eger EI II, Tinker JH. Determination and applications of MAC. Anesthesiology 1980; 53: 315-34.

12 Scheller MS, Saidman LJ, Partridge BL. MAC of sevoflurane in humans and the New Zealand white rabbit. Can J Anaesth 1988; 35: 153-6.

13 Ware JA, Coller BS. Platelet morphology, biochemistry, and function. In: Beutler E, Lichtman MA, Coller BS, 
Kipps TJ (Eds.). Hematology, 5th ed. New York: McGraw-Hill, 1995: 1161-201.

14 Moir $D D$. Blood loss during major vaginal surgery. A statistical study of the influence of general anaesthesia and epidural analgesia. Br J Anaesth 1968; 40: 233-9.

15 Thorud T, Lund I, Holme I. The effect of anesthesia on intraoperative and postoperative bleeding during abdominal prostatectomies: a comparison of neurolept anesthesia, halothane anesthesia and epidural anesthesia. Acta Anaesthesiol Scand 1975; 57: 83-8.

16 Keith I. Anaesthesia and blood loss in total hip replacement. Anaesthesia 1977; 32: 444-50.

17 Zorgniotti AW, Narins DJ, Dell'aria SL. Anesthesia, hemorrhage and prostatectomy. J Urol 1970; 103: 774-7.

18 Bollen $B A$, Tinker $J H$, Hermsmeyer $K$. Halothane relaxes previously constricted isolated porcine coronary artery segments more than isoflurane. Anesthesiology 1987; 66: 748-52.

19 Yamamoto $M$, Hatano $\Upsilon$, Kakuyama $M$, et al. Halothane and isoflurane preferentially inhibit prostanoid-induced vasoconstriction of rat aorta. Can J Anaesth 1994; 41: 991-5.

20 Brezinsky $M E$, Yanagisawa $A$, Darius $H$, Lefer $A M$. Anti-ischemic actions of a new thromboxane receptor antagonist during acute myocardial ischemia in cats. Am Heart J 1985; 110: 1161-7.

21 Obmori $M$, Kuzuya $T$, Kodama $K$, Nanto $S$, Kamada $T$, Tada $M$. Thromboxane $\mathrm{A}_{2}$ as an enhancing factor of coronary vasospasticity in variant angina. Jpn Circ J 1987; 51: 495-502.

22 Verheggen $R, S c h r o ̈ r ~ K$. The modification of plateletinduced coronary vasoconstriction by a thromboxane receptor antagonist. J Cardiovasc Pharmacol 1986; 8: 483-90. 